This is a self-archived - parallel published version of this article in the publication archive of the University of Vaasa. It might differ from the original.

\title{
Investigating the Association between Oil VIX and Equity VIX: Evidence from China
}

Author(s): Dutta, Anupam; Rothovius, Timo; Nikkinen, Jussi

Title: Investigating the Association between Oil VIX and Equity VIX:

Evidence from China

Year: $\quad 2020$

Version: Accepted version

Copyright (C) 2020 World Scientific Publishing Company. Electronic version of a chapter published in Risk Factors and Contagion in Commodity Markets and Stocks Markets, 25-46. https://doi.org/10.1142/9789811210242_0002

\section{Please cite the original version:}

Dutta, A., Rothovius, T. \& Nikkinen, J. (2020). Investigating the Association between Oil VIX and Equity VIX: Evidence from China. In: Goutte, S. \& Guesmi, K. (eds.) Risk Factors and Contagion in Commodity Markets and Stocks Markets, 25-46. Singapore: World Scientific. https://doi.org/10.1142/9789811210242_0002 


\title{
Investigating the Association between Oil VIX and Equity VIX: Evidence from China
}

\begin{abstract}
To the best of our knowledge, this is the initial study to investigate the linkages between implied volatilities of global crude oil and Chinese equity markets. At the empirical stage, the bivariate VARGARCH model has been adopted to assess the relationship between oil volatility index (OVX) and Chinese equity market volatility index (VXFXI). In addition, we also employ the VAR-AGARCH approach for robustness check. The major findings of our empirical analysis can be summarized as follows. First, we do not find any evidence of return spillover between these two implied volatility indices. Second, there exists a unidirectional volatility spillover running from oil to equity options. The results thus suggest that global oil market embodies a crucial role in predicting the Chinese equity market trends. We finally document that significant portfolio diversification benefits are possible if investors hold options in both the oil and equity markets. Our results are robust in that applications of different methods lead to similar conclusions. The findings have important implication for investors and policymakers who are interested in derivative pricing, portfolio rebalancing and risk management practices.
\end{abstract}

Keywords: OVX; VXFXI; Volatility spillover; VAR-GARCH model; Hedging effectiveness. 


\section{Introduction}

Although the associations between oil and equity markets have been extensively explored over the last few decades, there is no consensus about such relationships among the researchers and economists. To be specific, the results of previous studies are somewhat mixed. While some papers (e.g., Hammoudeh and Li, 2005; Basher and Sadorsky, 2006; Hammoudeh and Choi, 2007; Nandha and Faff, 2008; Kilian and Park, 2009) find a negative link between oil and stock returns, several others (e.g., Sadorsky, 2001; El-Sharif et al., 2005; Narayan and Narayan, 2010; Zhang and Chen, 2011; Arouri and Rault, 2012; Bouri, 2015a) document a positive association between these markets. In addition, few studies (Chen et al., 1986; Huang et al., 1996; Apergis and Miller, 2009; Zhu et al., 2014; Fang and You, 2014) even conclude that the markets under consideration do not move together.

Investigating the oil-stock link is vital, since variations in oil price may have substantial impacts on the stock market as well as the overall economy. Bouri (2015b), for instance, argues that oil price shocks can transmit into equity markets leading to immediate instabilities in financial markets and distant disruptions of economic activities. Fowowe (2013) also contends that high oil prices lead to a slower pace of economic activities and this may affect consumers and producers alike by dampening consumption and investment which adversely impacts the stock markets. Additionally, Ciner (2013) documents that oil prices have important influences over the stock returns mainly in two aspects. First, oil price shocks can cause changes in expected cash flows by their effect on the whole economy. Second, such shocks can impact the discount rate used to value equities by changing inflationary expectations. Moreover, Vo (2011) argues that a growth in oil prices can affect the future cash flows of a firm, either negatively or positively depending on 
whether the firm is producing or consuming oil. Chiou and Lee (2009) also add that if oil price has an impact on real output, an increase in oil price will depress aggregate stock prices suggesting a significant association between oil prices and equity market returns.

However, a central feature of all the studies cited above is that they have examined the association between oil and equity markets using the traditional price series and to date, very little is known about the connection between the implied volatility indices of these markets. In fact, such studies are almost non-existent. The only exceptions include Liu et al. (2013) and Maghyereh et al. (2016). Each of these articles sheds light on the importance of using the information content of implied volatility indices. Liu et al. (2013), for instance, recommend crude oil volatility index (OVX) to be a better indicator of oil price uncertainty arguing that implied volatilities not only contain historical volatility information, but also investors' expectation of future market conditions. The authors further add that the application of implied volatility indices, as measures of investor sentiment or risk aversion, could reveal more information than the historical price series. Moreover, Maghyereh et al. (2016) contend that the implied volatility linkages across markets are highly informative about the relation between market participants' expectations of future uncertainty.

In order to extend this scarce literature, we investigate the volatility transmission relationship between OVX and Chinese equity market volatility index (VXFXI). It is noteworthy that this study could not be possible without the introduction of VXFXI. The Chinese volatility index has been recently published by the Chicago Board Options Exchange (CBOE). We choose China for a number of reasons. First, China is the second-largest oil consumer surpassing Japan in $2003^{1}$.

\footnotetext{
${ }^{1}$ Source: US Energy Information Administration, 2014
} 
Moreover, the consumption of crude oil in China has significantly increased over the last decade. For example, its oil consumption amounts to 272.74 million tons in 2003 which reaches 507.40 million tons in 2013 implying an increase of $86.04 \%$. Second, it is currently the leading oilimporting nation as well. In 2003, China imports 91.02 million tons crude oil and this figure turns out to be 281.92 million tons in 2013, increasing by $209.73 \%$. Third, China's economy is prominently moved by its agricultural sector and the costs of agricultural products are significantly related to the transport sector which utilizes the highest amount of crude oil and petroleum-related products. Forth, China's metal market is also highly oil-intensive. Zhang and Tu (2016), for instance, document that changes in oil prices will affect the costs of the production process directly, further resulting in the changes of metal prices. Finally, China's oil import dependency exceeds $50 \%$, and the country's oil sector is greatly affected by the changes in International oil prices (Li et al., 2016). Due to this high external dependency on oil, the global oil price fluctuations inevitably impact relevant industries in China and further affect its overall economic activity. Nonetheless, there is surprisingly little literature investigating the association between the Chinese stock market and the global oil market (Chen and Lv, 2015). Our study aims to fill this void.

The present paper adds to the prior works of Liu et al. (2013) and Maghyereh et al. (2016) in several aspects. First, our study mainly concentrates on an emerging equity market. At the end of 2015 , emerging economies account for $58.1 \%$ of global energy consumption and most importantly, oil still remains the world's leading fuel, accounting for $32.9 \%$ of the overall energy consumption ${ }^{2}$. In addition, Basher and Sadorsky (2006) argue that oil price shocks are more severe in emerging economies than developed markets as the formers appear to be more energy sensitive.

\footnotetext{
${ }^{2}$ The information is sourced from www.bp.com
} 
Nevertheless, the existing literature is mostly focused on the developed markets and regions. The study thus makes a contribution by furthering the evidence on the impact of oil volatility shocks on emerging equity markets.

Second, unlike Liu et al. (2013) and Maghyereh et al. (2016), we have adopted two sophisticated bivariate GARCH approaches to examining the volatility transmission relationship between stock and oil VIX. Such methods are popularly known as VAR-GARCH and VAR-AGARCH developed by Ling and McAleer (2003) and McAleer et al. (2009) respectively. By doing so, we also contribute to the limited literature dealing with oil-stock volatility linkages. This can be considered as a major contribution, since the volatility of an asset is associated with the rate of information flow to a market and hence volatilities from different financial markets could affect each other. Arouri et al. (2011) also argue that understanding the volatility spillover between oil and equity markets provides efficient means of generating precise asset-pricing models and accurate forecasts of the volatility of both markets. Such analyses can help investors as well for choosing appropriate portfolio management strategies during periods of uncertainty in order to mitigate risk (Caporale et al., 2015).

Third, we utilize the estimated results of the bivariate GARCH models to analyze the portfolio risk. To be specific, we aim to find optimal portfolio allocations on the basis of oil and stock investments to examine whether oil market can be considered as an effective hedge against the unfavorable movements in the equity market option prices. Thus the results of our study could be useful to hedge oil price volatility risk and take proper asset allocation decisions. In addition, the findings could also be helpful to understand the dynamics between OVX and VXFXI to construct 
volatility related portfolio containing OVX and VXFXI from a perspective of diversifying the risk of the resultant portfolio (Liu et al., 2013).

Our findings, in short, suggest that volatility significantly runs from global oil to China's equity options. That is, the Chinese equity options are highly sensitive to oil volatility shocks. Such volatility linkages indicate that any turmoil in the oil market could bring uncertainty to the Chinese economic development and growth. Therefore, the government in China should adopt appropriate measures to reduce the impact of oil price uncertainty. For instance, increasing the use of biofuels could comprehensively minimize the dependency on imported oil. The findings further document that although China, as one of the major oil consumers, plays an important role in the international oil market, we do not find any significant volatility transmission from its stock market to the global oil market. Besides, the results also support the usefulness of including crude oil in the equity option portfolio for risk management purposes. Thus the findings have important implications for traders and investors in terms of portfolio diversification benefits. The outcomes of our empirical analysis are robust in that the employed methodologies lead to similar conclusions.

The rest of our study is structured as follows. The next Section reviews the related literature. Section 3 includes a brief description of the data. Section 4 outlines the bivariate GARCH methodologies. Results are discussed in Section 5. Section 6 concludes the paper.

\section{A brief review of related literature}


This section briefly reviews the previous literature focusing on the relationship between oil and Chinese stock markets. Although such literature is very limited, there are still some important scholarly works to be discussed. We begin with the study by Cong et al. (2008) who investigate the interactive relationships between oil price shocks and Chinese stock market using multivariate vector auto-regression. The authors find that oil price shocks do not show statistically significant impact on the real stock returns of most Chinese stock market indices, except for manufacturing index and some oil companies. Zhang and Chen (2011) assess the impact of global oil price shocks on China's stock market, using the ARJI(- $\left.\mathrm{h}_{\mathrm{t}}\right)$-EGARCH model. Separating the volatilities into expected, unexpected and negatively unexpected ones, the study reports that there are jumps varying in time in China's stock market, and that China's stock returns are correlated only with expected volatilities in world oil prices.

Moreover, Broadstock et al. (2012) examine how the dynamics of international oil prices affect energy related stock returns in China. To do so, the authors use the time varying conditional correlation and asset pricing models. The results suggest that the underlying stock market has a positive and significant reaction to the oil shocks, especially after the 2008 financial crisis. Besides, Li et al. (2012) explore the relationship between oil prices and the Chinese stock market at the sector level using a panel cointegration and Granger causality framework. Considering the effects of cross-sectional dependence and multiple structural breaks, the results indicate some evidence of structural breaks in the interaction between oil prices and Chinese sectoral stocks. When investigating the effects of oil price shocks on China's stock market returns, Wang et al. (2013) document that the Chinese stock market positively and strongly responds to oil-specific precautionary demand shocks. 
Furthermore, Caporale et al. (2015) inspect the time-varying impact of oil price uncertainty on stock prices in China using a bivariate VAR-GARCH-in-mean model. The study reveals that oil price volatility affects stock returns positively during periods characterized by demand-side shocks in all cases except the Consumer Services, Financials, and Oil and Gas sectors. Chen and Lv (2015) examine the asymptotic dependence between the Chinese stock market and the world crude oil market based on the Extreme Value Theory (EVT) and finds a positive extremal dependence. The study also investigates the contagion effect and shows that the dependence level tends to increase dramatically during the crisis period but that the simultaneous booms between these two markets decrease considerably after the crisis.

A recent study by Zhu et al. (2016) explores the dependence between real crude oil price changes and Chinese real industry stock market returns using the quantile regression approach. Empirical results reveal that the reaction of market returns to crude oil is highly heterogeneous across conditional distribution of industry stock returns. Additionally, adopting a Structural Vector Autoregression (SVAR) model, Li et al. (2016) decompose oil price changes into four components: oil supply shocks, global demand shocks, domestic demand shocks and precautionary demand shocks and then investigate the impacts of these oil price shocks on the stock returns of China's listed companies in the oil industrial chain. The study reports that the returns of the listed companies in the whole oil industrial chain benefit from appreciation in the oil price, the impacts of oil supply shocks and precautionary demand shocks are the most significant, and there is a structural change in the impacts of oil price shocks in 2012.

Reviewing the existing literature, we find only a single study by Luo and Qin (2016) that considers OVX to investigate the impact of implied oil volatility shocks on the Chinese stock market index 
and five sector returns. The empirical results suggest that oil volatility shocks positively affect the Chinese stock returns. More importantly, evidence indicates that the OVX shocks have significant and negative effects on the Chinese stock market while the impact of realized volatility shocks is negligible, especially after the recent financial crisis.

\section{Data}

In this paper, we investigate the uncertainty transmission relationship between the implied volatility indices OVX and VXFXI. The use of implied volatilities is beneficial, since such indices can reflect market's expectation for future near-term volatility. In addition, they are also considered as direct measures of market uncertainty.

The CBOE publishes OVX index, from the middle of 2007, as a measure of expected 30-day volatility of crude oil prices. The OVX considers real-time bid/ask quotes of nearby and second nearby options with at least 8 days to expiration, and weights these options to derive a constant, a 30-day estimate of the expected volatility (Liu et al., 2013).

Our sample starts in March 16, 2011 and ends in June 30, 2016, providing a total of 1382 observations. We pick this period because the VXFXI data are available from the commencing date of our sample. We collect the information on OVX and VXFXI from the Thomson Reuters DataStream database.

Table 1 displays the descriptive statistics for VXFXI and OVX (Panel A) along with their logarithmic change (Panel B). Now Panel A shows that OVX is more volatile than VXFXI, while the results of Panel B report the opposite. In addition, both these indices are positively skewed. 
We further report that the indices usually have kurtosis higher than 3, implying that these volatility series have leptokurtic distribution with asymmetric tails. The overall results thus imply that the volatility indices do not follow a standard normal distribution. Additionally, the Jarque-Bera test also rejects the null hypothesis of normality.

Fig.1 exhibits both OVX and VXFXI for the whole sample period. The figure illustrates that these volatility indices move closely together across time. In addition, several common spikes are observed in both indices during the sample period considered. It is interesting to note that these hikes are the consequences of either economic or political events. For instance, the spike arising during the beginning of 2011 can be accredited to the sovereign debt and banking problems in Italy and Spain for which the uncertainty in equity and oil markets increases evidently.

Table 2 reports the unit root tests for the indices. We conduct three different tests including Augmented Dickey-Fuller (ADF) test, the Phillips-Perron (PP) test and the Kwiatkowski-PhillipsSchmidt-Shin (KPSS) test to investigate the stationary condition. The ADF test and PP test have a null hypothesis of a unit root, while the KPSS test has a null hypothesis of no unit root. Observing these unit-root tests, we document that mainly the first-order differenced series are stationary for OVX, while for VXFXI we find stationarity even at the levels. Thus the unit root tests are somewhat mixed. However, it is at least established that both OVX and VXFXI are stationary when the first-order differenced series are considered.

[Table 1 about here]

[Table 2 about here] 


\section{[Fig. 1 about here]}

\section{Methodology}

\subsection{The VAR-GARCH Approach}

Previous studies use multivariate GARCH models for the purpose of assessing the volatility transmission linkages among diffrent financial markets. Such specifications include BEKK, CCC and DCC models. Important papers that employ these approaches to study the volatility spillover effects between oil and equity markets consist of Malik and Hammoudeh (2007), Malik and Ewing (2009), kang et al. (2009) and several others. However, these models often experience convergence problems and also involve computational complications (Arouri et al., 2012; Bouri, 2015a). In order to alleviate all these complexities, we consider applying the recently developed VARGARCH model proposed by Ling and McAleer (2003). This specification contains fewer parameters compared to other models such as BEKK and overcomes the convergence problem. Chang et al (2011), Arouri et al. (2011) and Bouri (2015a) have also chosen this model to estimate the volatility transmission relationship between oil and stock markets.

The initial step in the bivariate $\operatorname{VAR}(1)-\operatorname{GARCH}(1,1)$ methodology is to specify the following mean equation:

$$
\begin{aligned}
R_{t} & =D+\gamma R_{t-1}+\epsilon_{t} \\
\epsilon_{t} & =A_{t}^{1 / 2} \eta_{t}
\end{aligned}
$$

In equation (1), $R_{t}$ is a $2 \times 1$ vector of daily returns on oil and equity market implied volatility indices at time $t, D$ defines a $2 \times 1$ vector of constants, $\gamma$ denotes a $2 \times 2$ matrix of parameters 
measuring the effects of own lagged and cross mean transmissions between two markets, $\epsilon_{t}$ is the residual of the mean equation for the oil and stock options at time $t, \eta_{t}$ indicates a $2 \times 1$ vector of

independently and identically distributed innovations and $A_{t}^{1 / 2}=\operatorname{diag}\left(\sqrt{h_{t}^{s}}, \sqrt{h_{t}^{o}}\right)$, where $h_{t}^{s}$ and $h_{t}^{o}$, which indicate the conditional variances of stock and oil volatility index returns respectively, are given as

$$
\begin{aligned}
& h_{t}^{s}=d_{s}^{2}+b_{11}^{2} h_{t-1}^{s}+b_{21}^{2} h_{t-1}^{o}+a_{11}^{2} \varepsilon_{s, t-1}^{2}+a_{21}^{2} \varepsilon_{o, t-1}^{2} \\
& h_{t}^{o}=d_{o}^{2}+b_{12}^{2} h_{t-1}^{s}+b_{22}^{2} h_{t-1}^{o}+a_{12}^{2} \varepsilon_{s, t-1}^{2}+a_{22}^{2} \varepsilon_{o, t-1}^{2}
\end{aligned}
$$

Equations (2) and (3) allow us to explore how shocks and volatility are transmitted over time and across different indices. Now, the conditional covariance between oil and equity option returns is estimated as follows:

$$
h_{t}^{s o}=\rho_{t} \sqrt{h_{t}^{s}} \sqrt{h_{t}^{o}}
$$

where, $\rho_{t}$ is the conditional correlation between oil and stock returns at time $t$.

In order to capture the non-normality associated with oil and equity market indices, we employ the quasi-maximum likelihood estimation method to achieve the estimates of the parameters of our bivariate VAR(1)-GARCH $(1,1)$ model. Later, we utilize such estimates to compute the optimal weights and hedge ratios.

\subsection{The VAR-AGARCH Approach}

For the purpose of assessing the robustness of the results obtained from the VAR-GARCH approach, we now apply the bivariate VAR-AGARCH model proposed by McAleer et al. (2009). 
The advantage of using such specification is that it is capable of capturing the asymmetric relationships between returns (Lin et al., 2014). The bivariate VAR-AGARCH model assumes the following form:

$$
\begin{gathered}
h_{t}^{s}=d_{s}^{2}+b_{11}^{2} h_{t-1}^{s}+b_{21}^{2} h_{t-1}^{o}+a_{11}^{2} A\left(\varepsilon_{s, t-1}\right)^{2}+a_{21}^{2} A\left(\varepsilon_{o, t-1}\right)^{2}+B\left[\left(\varepsilon_{s, t-1}\right) \times\left(\left(\varepsilon_{s, t-1}\right)<0\right)\right] \\
h_{t}^{o}=d_{o}^{2}+b_{12}^{2} h_{t-1}^{s}+b_{22}^{2} h_{t-1}^{o}+a_{12}^{2} A\left(\varepsilon_{s, t-1}\right)^{2}+ \\
a_{22}^{2} A\left(\varepsilon_{o, t-1}\right)^{2}+B\left[\left(\varepsilon_{o, t-1}\right) \times\left(\left(\varepsilon_{o, t-1}\right)<0\right)\right](6)
\end{gathered}
$$

Within this framework, $A\left(\varepsilon_{s, t-1}\right)^{2}$ and $B\left[\left(\varepsilon_{s, t-1}\right) \times\left(\left(\varepsilon_{s, t-1}\right)<0\right)\right]$ along with $A\left(\varepsilon_{o, t-1}\right)^{2}$ and $B\left[\left(\varepsilon_{o, t-1}\right) \times\left(\left(\varepsilon_{o, t-1}\right)<0\right)\right]$ signify the relationship between a market's volatility and own lagged positive as well as negative returns respectively.

\section{Empirical results}

\subsection{Spillover effects}

The estimated results of our bivariate GARCH models have been reported in Tables 3 and 4 . Table 3 shows the findings obtained from the VAR-GARCH model, while the outcomes of the VARAGARCH approach are presented Table 4. These findings will allow us to investigate the association between first and second order moments of oil and equity market VIX. In these two tables, $h_{t-1}^{o}$ measures the conditional variance of the oil market at time $t-1$ and $h_{t-1}^{s}$ indicates the

conditional variance of the Chinese stock market at time $t-1$. The squared error terms $\varepsilon_{s, t-1}^{2}$ and $\varepsilon_{o, t-1}^{2}$ measure the effects of unexpected news or shocks in stock and oil markets respectively.

Now the findings, contained in Table 3, reveal that in each market past returns cannot be used to predict the current returns. This outcome clearly indicates that there does not exist any kind of 
short-term predictability in these markets. Moreover, we report that lagged OVX returns have a positive impact on VXFXI returns, albeit the corresponding parameter appears to be statistically insignificant. Such outcome suggests that there is no price spillover between these two volatility indices. This result is consistent with Fang and You (2014) who also document, using traditional price indices, an insignificant relationship between global oil and the Chinese stock market returns.

When turning to the estimates of the variance equations, our analysis further suggests that the Chinese implied volatility index does receive volatility from the international oil market volatility index. Thus the uncertainty caused by the global oil price volatility may have an impact on China's equity market. This result is expected due to the fact that China has to rely heavily on foreign oil, as its domestic production fails to meet the country's net oil demand. Moreover, oil remains the dominant fuel in China's industrial and transport sectors as well. In addition, over the last decade, China has been the most important driver of crude oil market due to its exponentially growing economy. The oil consumption in China has also substantially increased in recent years. Since China's economic growth is largely dependent on the global oil market, its financial markets seem to be highly susceptible to changes in world oil prices. Not surprisingly, there is no evidence of volatility transmission from the underlying stock market to the global oil market. This finding could be attributed to the fact that China is a leading oil-importing country, not an oil-exporting one, even though the increasing oil demand in China could exert an impact on the international oil market. Maghyereh et al. (2016) also document similar results while studying the association among implied volatility indices of global oil and different oil-importing markets. The authors show that the connection is largely dominated by the transmissions from the oil market to equity markets and not the other way around. 
The results presented in Table 3 further show that the Chinese stock market is also affected by the shock and news emanating from the crude oil market, while the reverse effect is not found to be statistically significant. Besides, both the stock as well as oil market option indices are affected by their own-lagged news and own past volatility. Finally, the estimate of constant conditional correlation (CCC) signals a strong correlation between OVX and VXFXI returns. Such a positive and significant correlation between these two volatility indices indicates potential for substantial gains from investing in both stock and oil assets.

Next the findings obtained from the VAR-AGARCH model, exhibited in Table 4, mirror those shown in Table 3. The results for this model coincide with those of the VAR-GARCH model due to the evidence of strong $\mathrm{ARCH}$ and GARCH effects and significant volatility spillover between oil and equity markets. Like the VAR-GARCH approach, the VAR-AGARCH method also confirms that the volatility spillover effect runs only from oil to stock market. As mentioned earlier, this finding is not unexpected since China is one of the largest oil-consuming nations and consequently, oil volatility shocks are likely to affect its equity mark et and hence the real economic activity. Li and Leung (2011) also contend that China is now an active participant in the world oil market, showing that oil prices in China are statistically maintaining a long-run relationship with major world oil prices. Therefore dynamics in the global oil price could affect the overall economic performance in China. Our findings further indicate the significance of the multivariate asymmetric effects for both market returns. The positive association between negative returns and volatility specifies that 'bad news' increases volatility in the markets while 'good news', despite being significant, does not have the same effect on volatility, as documented by the size of the coefficients. 
On the whole, our findings reveal that causality significantly runs from oil implied volatility to stock implied volatility. That is, the direction of causality between implied volatilities of equity and crude oil markets is dominated by oil. Thus China is evidently affected by the international oil price shocks. Previous literature explains the origins of this significant uncertainty transmission from oil market to equity market. Maghyereh et al. (2016), for instance, argue that oil price volatility may create comparable uncertainties regarding business cost, disposable income and consumer spending on energy using durable goods. In addition, volatile oil markets may also convey information on future global economic uncertainty. As a result, they can influence the volatility in global equity markets.

It is worth mentioning that the results of the bivariate GARCH models are consistent with a large number of existing studies (e.g., Malik and Ewing, 2009; Arouri et al., 2011, 2012; Bouri, 2015a,b and others) that report significant linkages between the oil volatility and equity volatilities. However, we differ from all these aforementioned studies in that our analyses concentrate on the linkages of implied volatilities that are used to price oil and equity options.

Moreover, the findings of our empirical analysis suggest that China should adopt appropriate policies to deal with oil market volatility. One possible policy could be the improvement of China's strategic oil reserves system to stable its oil price as the oil reserve is essential for those countries which are highly dependent on imported oil. Earlier studies such as Wang and Zhang (2014) and Zhang and $\mathrm{Tu}$ (2016) also argue that the oil reserve system reduces the impacts of oil supply shocks by stabilizing prices and eliminating the risk of oil supply by changing the oil inventory during the period of uncertainty. Additionally, the industrial sectors in China could make use of other energies, for example biofuels and solar energy, in order to minimize the oil dependency. Such 
renewable and environmental friendly energies should be exploited so as to diversify the energy structure and moderate the dependence on overseas oil (Wang and Zhang, 2014).

\section{[Table 3 about here]}

\section{[Table 4 about here]}

\subsection{Economic implications of the results}

We now utilize the estimates of our bivariate VAR-GARCH and VAR-AGARCH models to analyze how oil price risk can be hedged effectively. Suppose, an investor is holding options in the Chinese equity market and he would like to hedge his exposure against the adverse movements in oil option prices. Following Kroner and $\mathrm{Ng}$ (1998), the optimal portfolio weight can be constructed as follows:

$$
\omega_{t}^{s o}=\frac{h_{t}^{s}-h_{t}^{s o}}{h_{t}^{o}-2 h_{t}^{s o}+h_{t}^{S}}
$$

and,

$$
\omega_{t}^{s o}=\left\{\begin{array}{l}
0, \text { if } \omega_{t}^{s o}<0 \\
\omega_{t}^{s o}, \text { if } 0 \leq \omega_{t}^{s o} \leq 1 \\
1, \text { if } \omega_{t}^{s o}>1
\end{array}\right.
$$

where $\omega_{t}^{s o}$ refers to the weight of oil in a one-dollar portfolio consisting of oil and equity options at time $t, h_{t}^{S}$ and $h_{t}^{o}$ indicate the conditional covariances of stock and oil options respectively and $h_{t}^{s o}$ denotes the covariance term between these two markets at time $t$. The weight for the equity option is then given by $\left(1-\omega_{t}^{s o}\right)$.

Additionally, our results could also be exercised for computing optimal hedge ratios for the portfolio considered. Kroner and Sultan (1993) show that in order to minimize the risk of a 
portfolio, an investor should short $\beta_{t}$ dollar in the equity market which is one dollar long in the oil market, where $\beta_{t}$ is given by

$$
\beta_{t}^{s o}=\frac{h_{t}^{s o}}{h_{t}^{s}}
$$

The values of optimum portfolio weights $\omega_{t}^{s o}$ and hedge ratios $\beta_{t}^{s o}$ are presented in Table 5. These numbers reveal that the optimal weights provided by the VAR-GARCH approach are equal to 0.54 and 0.46 suggesting that for a $\$ 1$ portfolio, on average 54 cents should be invested in the oil market and the remaining 46 cents should be utilized on equity option. The corresponding weights produced by the VAR-AGARCH model are $53 \%$ and $47 \%$ respectively. Thus the overall outcomes suggest that investors holding assets in oil and Chinese equity options should invest more in oil than in stock in order to reduce the portfolio risk without impacting the expected return.

When turning to the hedge ratios results, we observe that the estimated risk minimizing hedge ratio for our VAR(1)-GARCH(1,1) model is 0.44 between oil and China's equity options. This finding shows that while holding a long position for $\$ 1$ in the oil market, investors should short 44 cents of the Chinese volatility index. The corresponding hedge ratio found from the VAR-AGARCH model amounts to 0.42 .

\section{[Table 5 about here]}

Following $\mathrm{Ku}$, Chen, and Chen (2007), we also obtain the hedging effectiveness (HE) for our oilstock portfolio. This can be determined by examining the realized hedging errors given as:

$$
H E=\frac{\text { Var }_{\text {unhedged }}-\text { Var }_{\text {hedged }}}{\text { Var }_{\text {unhedged }}}
$$


where $V_{\text {anhedged }}$ indicates the variance of the returns on the portfolio of stocks and $\operatorname{Var}_{\text {hedged }}$ denotes the variance of returns of the oil-stock portfolios. A higher HE of a given portfolio indicates the greater portfolio risk reduction which implies that the underlying investment strategy is deemed as a better hedging strategy (Arouri et al. 2011). Table 6 contains the unhedged portfolio variance, hedged portfolio variance and hedging effectiveness ratios computed using equation (9). These outcomes indicate that hedging strategies comprising oil and stock assets significantly minimize the portfolio risk. We further document that the reduction in variance due to the inclusion of oil in an optimal portfolio ranges from $30.27 \%$ for VAR-GARCH approach to $31.94 \%$ for VARAGARCH model. We thus conclude that significant portfolio diversification benefits are possible if investors hold options in both the oil and equity markets.

\section{[Table 6 about here]}

\section{Conclusion}

Although a strand of literature has investigated the associations between oil and stock markets over the years, examining such links using implied volatility indices rarely exists. In order to conceal this gap, the present study makes an attempt to focus on the linkages of implied volatilities that are used to price global oil and Chinese equity options. In particular, we explore the return and volatility transmission relationship between crude oil volatility index (OVX) and the Chinese equity market volatility index (VXFXI). In order to serve our purpose, we employ the VARGARCH as well as the VAR-AGARCH methodologies. The findings of our empirical analyses are robust in that both approaches yield similar results. Below are the summaries of our major findings. 
First, we document strong evidence of ARCH and GARCH effects in global oil and China's equity option markets. The sum of GARCH parameters also indicates high degree of persistence in the return fluctuations. Second, we do not find any evidence of return spillover between these two markets. Third, there exists a unidirectional volatility spillover running from oil implied volatility to equity implied volatility. The results thus suggest that global oil market embodies a crucial role in predicting the Chinese stock market trends. It is not surprising that the Chinese economy is very much sensitive to oil volatility shocks. The oil consumption in China has remarkably increased over the years and accordingly its important industries (e.g., agriculture and metal) become highly oil-intensive. Since China is heavily dependent on imported oil, its overall economy significantly reacts to the variations in global oil prices. Finally, the portfolio risk analysis shows that if investors diversify their portfolios by holding options in both global oil and the Chinese equity markets, the resulting portfolios would significantly improve on the original a great deal in terms of reducing market risk or increasing long-term benefits. That is, such investments could generate remarkable long-run gains in portfolio diversification.

The findings of our empirical analysis have important implication for investors and policymakers who are interested in derivative pricing, portfolio rebalancing and risk management practices. Investors, for example, could use our results to have better understanding of the cross-market linkages in terms of asset return and volatility transmission for building efficient business strategies and designing optimal portfolios. Policymakers, on the other hand, could implement effective measures during periods of uncertainty in order to reduce the oil price risk. Adopting such policies will then help to ensure a country's economy from global oil price shocks. 


\section{References}

Apergis, N., \& Miller, S. (2009). Do structural oil-market shocks affect stock prices? Energy Economics, 31(4), 569575.

Arouri, M., Jouini, J., and Nguyen, D., 2011. Volatility spillovers between oil prices and stock sector returns: implications for portfolio management. Journal of International Money and Finance 30, 1387-1405.

Arouri, M., Jouini, J., and Nguyen, D., 2012. On the impacts of oil price fluctuations on European equity markets: volatility spillover and hedging effectiveness. Energy Economics 34, 611-617.

Arouri, M., \& Rault, C. (2012). Oil prices and stock markets in GCC countries: Empirical evidence from panel analysis. International Journal of Finance and Economics, 17(3), 242-253. 
Basher, S., \& Sadorsky, P. (2006). Oil price risk and emerging stock markets. Global Finance Journal, 17(2), 224251.

Bouri, E., 2015a. Return and volatility linkages between oil prices and the Lebanese stock market in crisis periods. Energy 89, 365-71.

Bouri, E., 2015b. Oil volatility shocks and the stock markets of oil-importing MENA economies: A tale from the financial crisis. Energy Economics 51, 590-98.

Broadstock, D.C., Cao, H., \& Zhang, D.Y. (2012). Oil shocks and their impact on energy related stocks in China. Energy Economics, 34(6), 1888-1895.

Caporale, G.M., Ali, F.M., \& Spagnolo, N. (2015). Oil price uncertainty and sectoral stock return in China: A time varying approach. China Economic Review, 34, 311-321.

Chang, C.-L., Khamkaew, T., Tansuchat, R., McAleer, M., 2011. Interdependence of international tourism demand and volatility in leading ASEAN destinations. Tour. Econ. 17 (3), 481-507.

Chen, Q., Lv, X., 2015. The extreme-value dependence between the crude oil price and Chinese stock markets. Int. Rev. Econ. Financ. 39, 121-132.

Chen, N., Roll, R., \& Ross, S. (1986). Economic forces and the stock market. Journal of Business, 59, 383-403.

Chiou, J.S. and Lee, Y.H., 2009. Jump dynamics and volatility: Oil and the stock markets. Energy 34, 788-796.

Ciner, C., 2013. Oil and stock returns: Frequency domain evidence. Journal of International Financial Markets Institutions and Money 23, 1-11.

Cong, R.G., Wei, Y.M., Jiao, J.L., \& Fan, Y. (2008). Relationships between oil price shocks and stock market: An empirical analysis from China. Energy Policy, 36(9), 3544-3553.

El-Sharif, I., Brown, D., Nixon, B., \& Russel, A. (2005). Evidence on the nature and extent of the relationship between oil prices and equity values in the UK. Energy Economics, 27(6), 819-930.

Fang, C.R., \& You, S.Y. (2014). The impact of oil price shocks on the large emerging countries' stock prices: Evidence fromChina, India and Russia. International Review of Economics and Finance, 29, 330-338.

Fowowe B. Jump dynamics in the relationship between oil prices and the stock market: evidence from Nigeria. Energy 2013; 56: 31-8. 
Hammoudeh, S., \& Choi, K. (2007). Characteristics of permanent and transitory returns in oil-sensitive emerging stock markets: The case of GCC countries. Journal of International Financial Markets Institutions and Money, 17(3), 231-245.

Hammoudeh, S., \& Li, H. (2005). Oil sensitivity and systematic risk in oil-sensitive stock indices. Journal of Economics and Business, 57(1), 1-21.

Huang, R., Masulis, R., \& Stoll, H. (1996). Energy shocks and financial markets. Journal of Futures Markets, 16(1), $1-27$.

Kang, S.H., Kang, S.M., Yoon, S.M., 2009. Forecating volatility of crude oil markets. Energy Econ. 31, 119-125.

Kilian, L., \& Park, C. (2009). The impact of oil price shocks on the U.S. stock market. International Economic Review, 50(4), 1267-1287.

Kroner, K.F., and Ng, V.K., 1998. Modeling asymmetric movements of asset prices. Rev. Financ. Stud. 11, 844-871.

Kroner, K.F., and Sultan, J., 1993. Time dynamic varying distributions and dynamic hedging with foreign currency futures. J. Financ. Quant. Anal. 28, 535-551.

Ku, Y. H. H., Chen, H. C., \& Chen, K. H. (2007). On the application of the dynamic conditional correlation model in estimating optimal time-varying hedge ratios. Applied Economics Letters 14, 503-509.

Li, Q.M.; Cheng, K.; Yang, X.G. Response pattern of stock returns to international oil price shocks: From the perspective of China's oil industrial chain. Appl. Energy 2016. in press

Li, R., Leung, G.C.K., 2011. The integration of China into the world crude oil market since 1998. Energy Policy 39, $5159-5166$.

Li, S.F., Zhu, H.M., \& Yu, K. (2012). Oil prices and stock market in China: A sector analysis using panel cointegration with multiple breaks. Energy Economics, 34(6), 1951-1958.

Lin, B., Wesseh Jr, P.K., Appiah, M.O. 2014. Oil price fluctuation, volatility spillover and the Ghanaian equity market: Implication for portfolio management and hedging effectiveness. Energy Economics 42, 172-182.

Ling, S., McAleer, M. 2003. Asymptotic theory for a vector ARMA-GARCH model. Econometric Theory 19, 278308. 
Liu ML, Ji Q, Fan Y. How does oil market uncertainty interact with other markets: an empirical analysis of implied volatility index? Energy 2013; 55: 860-68.

Luo, X. and Qin, S. 2016. Oil price uncertainty and Chinese stock returns: New evidence from the oil volatility index. Finance Research letters, In press.

Maghyereh, A. I., Awartani, B., Bouri, E. 2016. The directional volatility connectedness between crude oil and equity markets: New evidence from implied volatility indexes. Energy Economics, 57: 78-93.

Malik, F. and Ewing, B.T., 2009. Volatility transmission between oil prices and equity sector returns. International Review of Financial Analysis 18, 95-100.

Malik, S., and Hammoudeh, S., 2007. Shock and volatility transmission in the oil, US and Gulf equity markets. International Review of Economics and Finance 17, 357-368.

McAleer, M., Hoti, S., Chan, F., 2009. Structure and asymptotic theory for multivariate asymmetric conditional volatility. Econ. Rev. 28, 422-440.

Nandha, M., \& Faff, R. (2008). Does oil move equity prices? A global view. Energy Economics, 30(3), 986-997.

Narayan, P., \& Narayan, S. (2010). Modelling the impact of oil prices on Vietnam's stock prices. Applied Energy, 87(1), 356-361.

Sadorsky, P. (2001). Risk factors in stocks returns of Canadian oil and gas companies. Energy Economics, 23(1), 1728.

Vo, M.T., 2011. Oil and stock market volatility: A multivariate stochastic volatility perspective. Energy Economics $33,956-965$.

Wang, Y., Wu, C., \& Yang, L. (2013). Oil price shocks and stock market activities: Evidence from oil-importing and oil-exporting countries. Journal of Comparative Economics, 41(4), 1220-1239.

Wang, X. and Zhang, C. “The impacts of global oil price shocks on China's fundamental industries,” Energy Policy, vol. 68, pp. 394-402, 2014.

Zhang, C.G., \& Chen, X.Q. (2011). The impact of global oil price shocks on China's stock returns: Evidence from the ARJI (-ht)-EGARCH model. Energy, 36(11), 6627-6633. 
Zhang, C. and Tu, X. 2016. The effect of global oil price shocks on China's metal markets. Energy Policy 90, 131139.

Zhu, H., Guo, Y., You, W., Xu, Y., 2016. The heterogeneity dependence between crude oil price changes and industry stock market returns in China: Evidence from a quantile regression approach. Energy Economics 55, 30-41.

Zhu, H.M., Li, R., \& Li, S.F. (2014). Modeling dynamic dependence between crude oil prices and Asia-Pacific stockmarket returns. International Review of Economics and Finance, 29, 208-223.

Table 1: Descriptive Statistics

\begin{tabular}{lccccc}
\hline Index & Mean & $\begin{array}{c}\text { Standard } \\
\text { Deviation }\end{array}$ & Skewness & Kurtosis & $\begin{array}{c}\text { Jarque-Bera } \\
\text { Test }\end{array}$ \\
\hline Panel A: Levels & & & & & \\
\hline VXFXI & 27.81 & 7.21 & 1.55 & 5.84 & $1025.26^{* * *}$ \\
OVX & 34.01 & 12.51 & 0.59 & 2.83 & $82.10^{* * *}$ \\
\hline Panel A: Logarithmic change & & & & & $1899.09^{* * *}$ \\
\hline VXFXI & -.009 & 2.19 & 1.16 & 8.25 & $10785.80^{* * *}$ \\
OVX & -.003 & 2.11 & 1.07 & 16.52 & \\
\hline
\end{tabular}


Notes: This table reports the main descriptive statistics for different indices studied. $* * *$ indicates statistical significance at $1 \%$ level.

Table 2: Results of unit root tests

\begin{tabular}{|c|c|c|c|c|c|c|}
\hline \multirow[t]{2}{*}{ Sector } & \multicolumn{2}{|c|}{ ADF Tests } & \multicolumn{2}{|c|}{ PP Tests } & \multicolumn{2}{|c|}{ KPSS Tests } \\
\hline & Level & $\begin{array}{l}1 \mathrm{st} \\
\text { Difference }\end{array}$ & Level & $\begin{array}{l}\text { 1st } \\
\text { Difference }\end{array}$ & Level & $\begin{array}{l}\text { 1st } \\
\text { Difference }\end{array}$ \\
\hline VXFXI & $-4.67 * * *$ & $-36.60 * * *$ & $-4.31 * * *$ & $-37.69 * * *$ & 0.44 & 0.03 \\
\hline OVX & $-2.75^{*}$ & $-39.10 * * *$ & -2.51 & $-40.45 * * *$ & $1.01 * * *$ & 0.11 \\
\hline
\end{tabular}

Notes: This table shows the results for the ADF, PP and KPSS tests. ${ }^{* * *}$ and $*$ indicate statistical significance at $1 \%$ and $10 \%$ levels respectively. 
Table 3: Results of the VAR-GARCH model

\begin{tabular}{lcc}
\hline Independent Variable & VXFXI & OVX \\
\hline$r_{t-1}^{S}$ & $-0.0002(.99)$ & $-0.0356(.18)$ \\
$r_{t-1}^{o}$ & $0.0357(.15)$ & $-0.0361(.24)$ \\
$\varepsilon_{s, t-1}^{2}$ & $0.1419(.00)^{* * *}$ & $0.0118(.50)$ \\
$\varepsilon_{o, t-1}^{2}$ & $-0.0272(.00)^{* * *}$ & $0.0726(.00)^{* * *}$
\end{tabular}




$\begin{array}{lll}h_{t-1}^{s} & 0.7327(.00)^{* * *} & 0.0489(.85) \\ h_{t-1}^{o} & 0.5220(.00)^{* * *} & 0.6404(.00)^{* * *} \\ \text { CCC } & & \\ \text { VXFXI } & 1.000 & 1.000 \\ \text { OVX } & 0.4569(.00)^{* * *} & \\ \text { Log Likelihood } & -5670.98 & \end{array}$

Notes: This table reports the outcomes for the VAR-GARCH model. $r_{t-1}^{s}$ refers to the return on the Chinese equity options at time $t-1$ and $r_{t-1}^{o}$ denotes the same for the oil market. In addition, $h_{t-1}^{o}$ measures the conditional variance of the oil market option returns at time $t-1$ and $h_{t-1}^{S}$ indicates the conditional variance of stock market option returns at time $t$ - 1 . The squared error terms $\varepsilon_{s, t-1}^{2}$ and $\varepsilon_{o, t-1}^{2}$ measure the effects of unexpected news or shocks in stock and oil markets respectively. CCC denotes the constant conditional correlation between VXFXI and OVX. *** indicates statistical significance at $1 \%$ level. Values in parentheses indicate $p$-values.

\section{Table 4: Results of the VAR-AGARCH model}

\begin{tabular}{lcc}
\hline Independent Variable & VXFXI & OVX \\
\hline$r_{t-1}^{S}$ & $-0.0079(.78)$ & $0.0412(.13)$ \\
$r_{t-1}^{o}$ & $0.0438(.12)$ & $-0.0069(.82)$ \\
$A\left(\varepsilon_{s, t-1}\right)^{2}$ & $0.0270(.00)^{* * *}$ & $0.0024(70)$ \\
$A\left(\varepsilon_{o, t-1}\right)^{2}$ & $-0.0218(.00)^{* * *}$ & $0.0115(.00)^{* * *}$ \\
$B\left[\left(\varepsilon_{s, t-1}\right) \times\left(\left(\varepsilon_{s, t-1}\right)<0\right)\right]$ & $0.0339(.00)^{* * *}$ &
\end{tabular}




$\begin{array}{llc}B\left[\left(\varepsilon_{o, t-1}\right) \times\left(\left(\varepsilon_{o, t-1}\right)<0\right)\right] & 0.0359(.00)^{* * *} \\ h_{t-1}^{s} & 0.8320(.00)^{* * *} & 0.0054(.87) \\ h_{t-1}^{o} & 0.1053(.00)^{* * *} & 0.7298(.00)^{* * *} \\ \text { CCC } & & \\ \text { VXFXI } & 1.000 & 1.000 \\ \text { OVX } & 0.4493(.00)^{* * *} & \\ \text { Log Likelihood } & -5627.94 & \end{array}$

Notes: This table reports the outcomes for the VAR-AGARCH model. $r_{t-1}^{S}$ refers to the return on the Chinese equity options at time $t-1$ and $r_{t-1}^{o}$ denotes the same for the oil market. In addition, $h_{t-1}^{o}$ measures the conditional variance of the oil market option returns at time $t-1$ and $h_{t-1}^{S}$ indicates the conditional variance of stock market option returns at time $t$-1. The squared error terms $\varepsilon_{s, t-1}^{2}$ and $\varepsilon_{o, t-1}^{2}$ measure the effects of unexpected news or shocks in stock and oil markets respectively. CCC denotes the constant conditional correlation between VXFXI and OVX. *** indicates statistical significance at $1 \%$ level. Values in parentheses indicate $p$-values.

Table 5: Portfolio Optimum Weights and Hedge Ratios

\begin{tabular}{lcl}
\hline Model $\downarrow$ & $\omega_{t}^{s o}$ & $\beta_{t}^{s o}$ \\
\hline VAR-GARCH & 0.54 & 0.44 \\
VAR-AGARCH & 0.53 & 0.42 \\
\hline
\end{tabular}


Notes: This table shows the average optimal weights along with hedge ratios for the oil-stock portfolio. The crude oil volatility index is considered as the oil asset, while the Chines equity market volatility index is employed to represent the stock market.

Table 6: Hedging Effectiveness

\begin{tabular}{lccc}
\hline Model $\downarrow$ & Variance (Unhedged) & Variance (Hedged) & HE (\%) \\
\hline VAR-GARCH & 4.79 & 3.34 & 30.27 \\
VAR-AGARCH & 4.79 & 3.26 & 31.94
\end{tabular}

Notes: This table presents the hedging effectiveness for the oil-stock portfolio. Var unhedged indicates the variance of the returns on the portfolio of equity option and $V a r_{\text {hedged }}$ denotes the variance of returns of the oil-stock portfolio. HE implies the hedging effectiveness. 



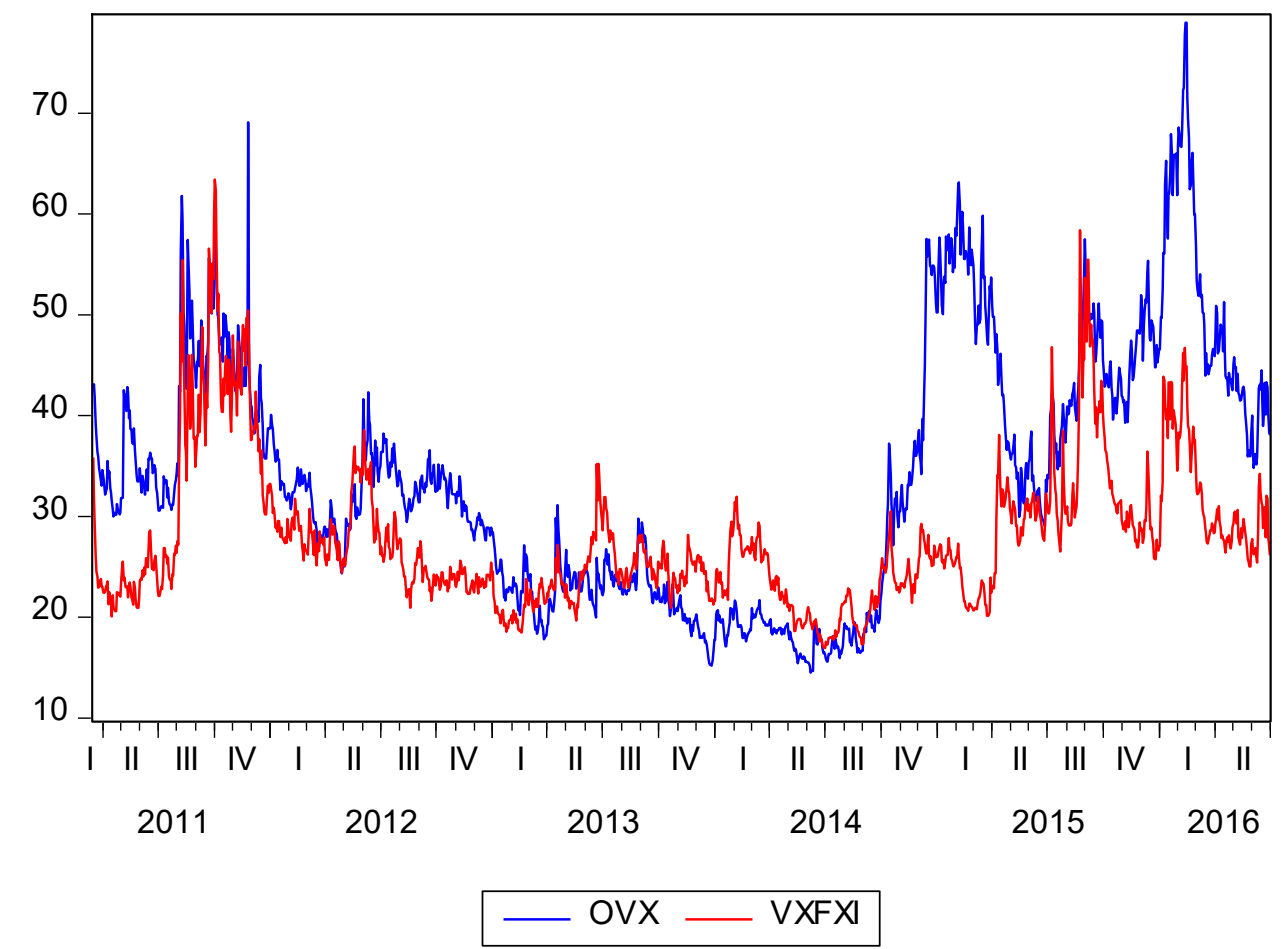

Fig. 1: OVX and VXFXI for the whole sample period 